\title{
EVALUATION OF OXIDATIVE STRESS IN RATS TREATED SUBCHRONICALLY WITH ETHANOL
}

\author{
Stefka Valcheva-Kuzmanova ${ }^{1}$, Miroslav Eftimov ${ }^{1}$, Krasimir Kuzmanov ${ }^{2}$ \\ ${ }^{1}$ Department of Preclinical and Clinical Pharmacology and Toxicology and \\ ${ }^{2}$ Vivarium, Medical University of Varna
}

\begin{abstract}
PURPOSE: The aim of the present study was to evaluate the oxidative stress in male Wistar rats treated subchronically with ethanol.

MATERIAL AND METHODS: Ethanol was applied orally for 45 days. The daily dose of $7,9 \mathrm{~g} / \mathrm{kg}$ as a $20 \%$ solution was divided in two equal treatments. Oxidative stress was evaluated by the concentration of thiobarbituric acid reacting substances (TBARS), markers of lipid peroxidation. TBARS were determined in rat serum, liver, kidneys, brain and testes.

RESULTS: Ethanol-induced toxicity was evidenced by a significantly lower $(p<0,001)$ weight gain of ethanoltreated rats in comparison with distilled water-treated controls. TBARS in ethanol-treated rats were significantly increased $(\mathrm{p}<0,05)$ in serum $(59,33 \pm 7,5 \mathrm{nmol} / \mathrm{mL}$ vs the control value of $41,55 \pm 3,9 \mathrm{nmol} / \mathrm{mL})$ and in testes $(123,98 \pm 13,5 \mathrm{nmol} / \mathrm{g}$ vs the control value of $89,25 \pm 7,5 \mathrm{nmol} / \mathrm{g})$. They were, however, not significantly elevated in the liver, kidneys and brain. This effect in the liver was consistent with the insignificant elevation of liver enzymes in the serum of ethanol-treated rats.

CONCLUSION: The results from this study showed that in ethanol-treated rats, lipid peroxidation products were mostly increased in serum and testes as well the latter being more exposed to oxidative stress than other organs examined such as liver, kidneys and brain.
\end{abstract}

Key words: subchronical ethanol, oxidative stress, thiobarbituric acid reactive substances, rats

\section{INTRODUCTION}

Exposure to high alcohol doses results in many pathophysiologic changes in cellular functions caused by the alcohol itself and the effects of its metabolism (i.e., generation of acetaldehyde, nicotinamide adenine dinucleotide, free radicals, and oxidative stress).

\section{Address for correspondence:}

Stefka Valcheva-Kuzmanova, $M D, P h D$

Dept. of Preclinical and Clinical Pharmacology and

Toxicology, Medical University of Varna,

55 Marin Drinov Str., 9002 Varna, Bulgaria

E-mail:stefkavk@yahoo.com

Received: August 30, 2012

Accepted: January 15, 2013
It is now clear that various mediators have been implicated in ethanol-induced tissue injury, however, the role of oxidative stress and free radical damage is thought to be of particular importance. Oxidative stress is characterized by an imbalance between reactive oxygen species (ROS) production and removal. ROS are released as byproducts of ethanol metabolism (2). Elevated ROS production together with ethanolinduced inhibition of the antioxidative system $(6,9)$ generates a state of oxidative stress and leads, finally, to damage of cellular macromolecules such as DNA, lipids and proteins. The eruption of ROS is capable of propagating lipid peroxidation as manifested by the increased level of thiobarbituric acid reactive substances (TBARS). Ethanol-induced oxidative stress is not restricted to the liver, where ethanol is actively oxidized, but can affect various extrahepatic tissues as 
shown by experimental data obtained in rat models of acute and chronic ethanol intoxication.

The review of literature shows that most studies investigate the effects of alcohol in one organ (predominantly, the liver or the brain). There are fewer investigations of the effects of alcohol in the kidneys and the testes.

The aim of the present study was to evaluate and compare the oxidative stress in the serum, liver, kidneys, brain and testes of male Wistar rats treated subchronically with ethanol. The index of oxidative stress was the level of lipid peroxidation products (thiuobarbituric acid reactive substances).

\section{MATERIAL AND METHODS}

\section{Experimental substances}

Absolute ethanol and diethylether were purchased from Geya 99 (Bulgaria). Malondialdehyde was obtained from Sigma-Aldrich Company (Germany). Thiobarbituric acid and all other chemicals needed for the biochemical analyses were received from Merck (Germany). The assay kits for the measurement of liver enzymes (aspartate aminotransferase, alanine aminotransferase and alkaline phosphatase) were obtained from Biosystems S.A. (Barcelona, Spain) distributed by IVD Bulgaria.

\section{Animals and experimental treatments}

The study was carried out on 20 male Wistar rats (weight 220-250 g). The animals were housed at a temperature of $22 \pm 2^{\circ} \mathrm{C}$ and given normal pelleted diet and water ad libitum.

All procedures concerning animal treatment and experimentation were conducted in compliance with the national laws and policies and in conformity with the international guidelines (EEC Council Directive 86/609, IL 358, 1, December 12, 1987).

The animals were divided into two groups of 10 rats: a control and an ethanol group. All the animals were treated orally through an orogastric cannula twice daily (at 8 a.m. and 2 p.m.) for 45 days. The control group received two doses of distilled water $(25 \mathrm{ml} / \mathrm{kg})$. The ethanol group received ethanol at a daily dose of $7,9 \mathrm{~g} / \mathrm{kg}$ prepared as a $20 \%$ solution divided in two applications of $25 \mathrm{ml} / \mathrm{kg}$. Body weight was measured weekly and weight gain was calculated.

\section{Serum and homogenate preparation}

On the $46^{\text {th }}$ day, the animals were anaesthetized with diethylether 24 hours after the last treatment. Blood was collected from the sublingual veins. It was centrifuged at $2000 \mathrm{rpm}$ for $10 \mathrm{~min}$ and serum was obtained for the measurement of lipid peroxidation products.

After the dacapitation of the animals, rat liver, kidneys, brain and testes were frozen at $-18^{\circ} \mathrm{C}$ till the biochemical analyses. In order to prepare organ homogenates, $1 \mathrm{~g}$ of each organ was minced in a beaker with a pair of scissors and then homogenized with ice cold Tris/HCl buffer $(50 \mathrm{mM}, \mathrm{pH} 7,4)$ in 1:10 ratio for liver, kidneys and testes and 1:5 ratio for brain.

\section{Measurement of lipid peroxidation products}

Lipid peroxidation levels were estimated by the thiobarbituric acid (TBA) reaction using the method of Ohkawa et al. (12). This method measured spectrophotometrically the colour produced by the reaction of TBA with lipid peroxides, TBARS at $532 \mathrm{~nm}$. Briefly, $200 \mu \mathrm{L}$ serum or homogenate was precipitated with an equal volume of $8.1 \%$ sodium dodecyl sulfate. The reaction mixture was acidified with $500 \mu$ L of aceticacidbuffer (pH3,4). Subsequently, $500 \mu \mathrm{L}$ of $0,8 \%$ TBA was added and allowed to form adducts with various oxidative products of lipid peroxidation at $95^{\circ} \mathrm{C}$ for 2 hours. After being cooled, the sample was centrifuged at $2000 \mathrm{rpm}$ for $10 \mathrm{~min}$ at room temperature, and the absorbance of the supernatant was measured with Aurius 2021 UV-VIS spectrophotometer (Cecil Instruments Ltd, UK). TBARS were determined in $\mathrm{nmol} / \mathrm{mL}$ serum and $\mathrm{nmol} / \mathrm{g}$ tissue. Malondialdehyde, the major reactive aldehyde resulting from the peroxidation of biological membrane polyunsaturated fatty acids, was used as a standard.

\section{Measurement of liver enzymes}

Liver enzymes aspartate aminotransferase (AST), alanine aminotransferase (ALT) and alkaline phosphatase (ALP) were measured by spectrophotometric methods in accordance with the kits manufacturer's instructions.

\section{Statistical analysis}

The results were assessed by means of Student's t-test. A value of $\mathrm{p}<0,05$ was considered statistically 
significant. Results were presented as mean \pm S.E.M. GraphPad Prism statistical software was used.

\section{RESULTS}

\section{Weight gain}

The mean body weight gain for the entire experimental period in the control group was $52,5 \pm 3,7 \mathrm{~g}$. In the ethanol group it was $25,0 \pm 4,4 \mathrm{~g}$ that was significantly lower $(\mathrm{p}<0,001)$ than the control value.

\section{Lipid peroxidation products (TBARS)}

TBARS levels in rat liver, kidneys and brain were given in Table 1.

Ethanol treatment induced only a slight TBARS elevation in rat liver (104\% of the control value), kidneys (112\% of the control value) and brain (104\% of the control value).

Table 1. Levels of TBARS in rats treated subchronically with distilled water (Control) or ethanol at a dose of $7,9 \mathrm{~g} / \mathrm{kg}$ (Ethanol)

\begin{tabular}{l|cc|}
\hline \multirow{2}{*}{$\begin{array}{l}\text { Organ TBARS } \\
\text { (nmol/g) }\end{array}$} & \multicolumn{2}{|c|}{ Groups } \\
\cline { 2 - 3 } & Control & Ethanol \\
\hline Liver TBARS & $291,8 \pm 13,5$ & $303,8 \pm 23,3$ \\
Renal TBARS & $258,8 \pm 15,6$ & $288,8 \pm 11,6$ \\
Brain TBARS & $84,3 \pm 7,8$ & $87,8 \pm 5,6$ \\
\hline \hline
\end{tabular}

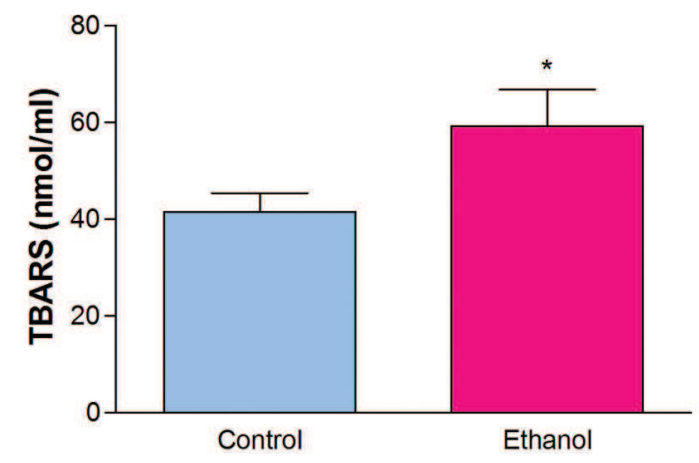

Fig. 1. Serum levels of TBARS in rats treated subchronically with distilled water (Control) or ethanol at a dose of $7,9 \mathrm{~g} / \mathrm{kg}$ (Ethanol) ${ }^{*} p<0,05$ vs Control
In rats belonging to the ethanol group TBARS in serum $(59,3 \pm 7,5 \mathrm{nmol} / \mathrm{mL})$ were significantly higher $(p<0,05)$ than the control level of $41,6 \pm 3,9$ $\mathrm{nmol} / \mathrm{mL}$. Thus, serum TBARS in ethanol-treated rats were $143 \%$ of the control value (Fig. 1).

TBARS contents in testes were presented in Fig. 2. In rats from the control group, TBARS content was $86,1 \pm 5,9 \mathrm{nmol} / \mathrm{g}$ tissue. The ethanol group presented with a significantly higher TBARS level $(\mathrm{p}<0,05)$ in the testes $(124,0 \pm 13,5 \mathrm{nmol} / \mathrm{g} ; 144 \%$ of the control value).

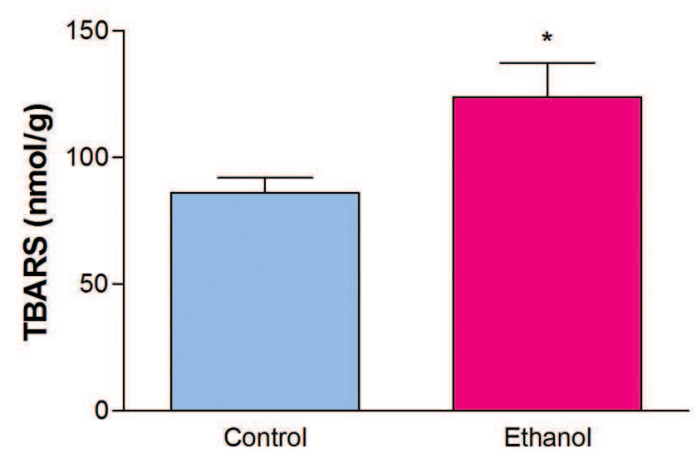

Fig. 2. Levels of TBARS in the testes of rats treated subchronically with distilled water (Control) or ethanol at a dose of $7,9 \mathrm{~g} / \mathrm{kg}$ (Ethanol) ${ }^{*} p<0,05$ vs Control

\section{Liver enzymes}

Liver enzyme levels were demonstrated in Table 2. Ethanol treatment caused an AST elevation to a level that was $164 \%$ of the control value. ALT and ALP were elevated to a smaller extent to levels which were $124 \%$ and $119 \%$ of the control values, respectively.

Table 2. Serum levels of liver enzymes of rats treated subchronically with distilled water (Control) or ethanol at a dose of $7,9 \mathrm{~g} / \mathrm{kg}$ (Ethanol)

\begin{tabular}{l|c|c|}
\hline \multirow{2}{*}{ Enzyme (U/L) } & \multicolumn{2}{|c|}{ Groups } \\
\cline { 2 - 3 } & Control & Ethanol \\
\hline AST & $78,2 \pm 7,9$ & $127,9 \pm 37,7$ \\
ALT & $21,4 \pm 1,8$ & $26,5 \pm 5,2$ \\
ALP & $155,3 \pm 16,7$ & $185,4 \pm 30,0$ \\
\hline
\end{tabular}




\section{DISCUSSION}

Alcohol at high doses is toxic for the organism. During ethanol metabolism, potentially dangerous byproducts including ROS are generated (7). Certain byproducts of alcohol metabolism may be more toxic than alcohol itself. In this study, the toxic affect of alcohol was demonstrated by the low weight gain of ethanol-treated rats.

Numerous studies have indicated that free radicals or ROS such as a-hydroxy ethyl radical, superoxide and hydroxy radicals are responsible for ethanol-induced oxidative stress $(5,10)$. All these radicals possess a great potential to react rapidly with lipids, which in turn leads to lipid peroxidation. The lipid peroxides are potentially toxic and can damage most kinds of cells (3). The TBARS assay is an ex vivo method of measuring the extent of lipid peroxidation.

The present study demonstrates the effects of ethanol on oxidative stress in different rat tissues. Ethanol treatment results in a significant TBARS increase in the testes and an insignificant one in the liver, kidneys and brain. These findings are in accordance with other investigations showing that acute and chronic exposure to ethanol administered either orally, or intraperitoneally leads to increased free radical and lipid peroxide formation in rat testes $(4,8,15)$. Thus, ROS generation and lipid peroxidation might be an important mechanism of ethanol toxicity in the testes $(1,13,14)$.

In the present study, a significant TBARS increase in rat serum was observed. As circulating peroxidation products originate from different organs, the elevated TBARS in serum reflects, probably, the oxidative stress in the whole organism.

The results from this study are not in agreement with studies that have demonstrated that alcohol most notably affects the central nervous system and the liver $(5,7,11)$. In the present study, the alcohol dose or duration of administration were, probably, not sufficient to cause significant effects in the liver, kidneys and brain. The reactive metabolites produced during ethanol metabolism disrupt cell membranes and release enzymes such as AST, ALT and ALP in the blood thereby increasing their levels. In this investigation the insignificant TBARS elevation in the liver correlates with the insignificant elevation of liver enzymes in rat serum.

\section{CONCLUSION}

Ethanol applied subchronically to rats caused a significant increase of lipid peroxidation products in serum and testes as well as an insignificant elevation of these products in the liver, kidneys and brain. Thus, among the examined organs, the testes proved to be affected to the greatest extent by alcohol toxicity.

\section{REFERENCES}

1. Aitken, J. R., C. Krausz, D. Burkingham. Relationships between biochemical markers for residual sperm cytoplasm, reactive oxygen species generation and the presence of leukocytes and precursor germ cells in human sperm suspensions.- Mol. Reprod. Dev., 39, 1994, No 3, 268-279.

2. Albano, E. Alcohol, oxidative stress and free radical damage.- Proc. Nutr. Soc., 65, 2006, No 3, 278-290.

3. Das, S. K., D. M. Vasudevan. Alcohol-induced oxidative stress.- Life Sci., 81, 2007, No 3, 177-187.

4. Dosumu, O. O., F. I. O. Duru, A. A. Osinubi, A. A. Oremosu, C. C. Noronha. Influence of virgin coconut oil (VCNO) on oxidative stress, serum testosterone and gonadotropic hormones (FSH, LH) in chronic ethanol ingestion.- Agric. Biol. J. North. Am., 1, 2010, No 6, 1126-1132.

5. Hoek, J. B., J. G. Pastorino. Ethanol, oxidative stress and cytokine induced liver injury.- Alcohol, 27, 2002, No 1, 63-68.

6. Koch, O. R., G. Pani, S. Borrello, R. Colavitti, A. Cravero, $S$. Farrè, et al. Oxidative stress and antioxidant defenses in ethanol-induced cell injury.- Mol. Aspects Med., 25, 2004, No 1-2, 191-198.

7. Lieber, C. S. Alcoholic fatty liver: its pathogenesis and mechanism of progression to inflammation and fibrosis.- Alcohol, 34, 2004, No 1, 9-19.

8. Maneesh, M., H. Jayalekshmi, S. Dutta, A. Chakrabarti, D. M. Vasudevan. Effect of chronic ethanol administration on testicular antioxidant system and steroidogenic enzyme activity in rats.Indian J. Exp. Biol., 43, 2005, No 5, 445-449. 
9. Nath, B., G. Szabo. Alcohol-induced modulation of signaling pathways in liver parenchymal and nonparenchymal cells: implications for immunity.Semin. Liver Dis., 29, 2009, No 2, 166-177.

10. Nordmann, R., C. Ribiere, H. Rouach. Implications of free radical mechanisms in ethanol induced cellular injury.- Free Radical Biol. Med., 12, 1992, No 3, 219-232.

11. Nwozo, S. O., B. E. Oyinloye. Hepatoprotective effect of aqueous extract of Aframomum melegueta on ethanol-induced toxicity in rats.Acta Biochim. Pol., 58, 2011, No 3, 355-358.

12. Ohkawa, H., N. Ohishi, K. Yagi. Assay for lipid peroxides in animal tissues by thiobarbituric acid reaction.- Anal. Biochem., 95, 1979, No 2, 351-358.
13. Oner-Iyidogan, Y., F. Gurdol, P. Oner. The effects of acute melatonin and ethanol treatment on antioxidant enzyme activities in rat testes.Pharmacol. Res., 44, 2001, No 1, 44-49.

14. Peltola, V., I. Huhtaniemi, T. M. Ketala, M. Ahotupa. Induction of lipid peroxidation during steroidogenesis in the rat testis.- Endocrinology, 137, 1996, No 1, 105-112.

15. Taati, M., M. Alirezaei, M. H. Meshkatalsadat, B. Rasoulian, A. Kheradmand, S. Neamati. Antioxidant effects of aqueous fruit extract of Ziziphus jujuba on ethanol-induced oxidative stress in the rat testes.- Iranian J. Vet. Res. Shiraz Univ., 12, 2011, No 1, 39-45. 